Original Research Article

\title{
A study on management of oral cancer in a tertiary care hospital
}

\author{
Mangala Srinivas ${ }^{1}$, Ravichandra Volabailu ${ }^{1 *}$, Jayarama Shetty K. ${ }^{2}$, Sangeeta Nath Sharma ${ }^{1}$
}

${ }^{1}$ Department of Pharmacology, ${ }^{2}$ Department of Oncology, K. S. Hegde Medical Academy, Nitte University, Mangaluru,

Karnataka, India

Received: 21 November 2017 Accepted: 28 December 2017

*Correspondence to:

Dr. Ravichandra Volabailu, Email: ravi75chandra@ yahoo.co.in

Copyright: (C) the author(s), publisher and licensee Medip Academy. This is an openaccess article distributed under the terms of the Creative Commons Attribution NonCommercial License, which permits unrestricted noncommercial use, distribution, and reproduction in any medium, provided the original work is properly cited.

\begin{abstract}
Background: Oral cancers form nearly $30 \%$ of the cancers. The most effective way of combating oral cancer is by early diagnosis followed by concurrent chemo-radiotherapy which is the most popular approach in current practice. The adverse effects seen in oral cancer patient's due to their treatment are nausea and vomiting, mucositis, constipation, diarrhoea, fatigue and radiation dermatitis. Polypharmacy is due to variety of treatment options in oral cancer patients, which needs to be addressed.

Methods: Over a period of 18 months, the in-patient records of 79 patients with oral cancers, admitted to oncology ward of Justice K. S. Hegde Charitable Hospital, Mangalore, were scrutinized and the data collected in a specially designed proforma. Descriptive analysis of the data was done.

Results: Required data was collected from 79 patients, out of which $55.7 \%$ of the patients underwent surgery and later received chemotherapy and radiotherapy. Most commonly seen adverse effects due to treatment were weight loss (75.9\%), reduced appetite $(67.1 \%)$, fatigue $(75.9 \%)$, pain $(79.7 \%)$ and skin discoloration (50.6\%), etc. Various classes of adjuvant drugs were used for complications caused due to the treatment of oral cancers. Drugs like topical applicant/mouth washes constituted the bulk of the prescriptions (22\%) followed by nutritional supplements (15.34\%), NSAID/opioids (12.76\%) hematinic (12.59\%) and other groups of drugs were also used.

Conclusions: Present study helped us to plan evidence based strategies to reduce or prevent post treatment complications. Most of the adverse effects were treated accordingly to keep the patient comfortable.
\end{abstract}

Keywords: Chemotherapy, Oral cancer, Polypharmacy, Radiotherapy

\section{INTRODUCTION}

Oral cancer is a heterogeneous group of cancers arising from different parts of the oral cavity with different predisposing factors, prevalence, and treatment outcomes. ${ }^{1}$ The most common cancer is related to head and neck squamous cell carcinoma (HNSCC) and the majority out of this is oral squamous cell carcinomas (OSCC). ${ }^{2}$

Various etiological factors have been suspected in the development of cancer of mouth like tobaccosmoking/chewing, betel quid chewing, alcohol, sunlight, nutritional deficiencies, infections / Immune deficiency and oral hygiene. ${ }^{3,4}$

The main aim of treating cancer of the oral cavity is to efface the cancer, preserve or restore form and function, minimize the complications of treatment and finally prevent recurrence. In order to achieve these goals, the currently available treatment modalities include surgery, radiotherapy, chemotherapy, combined modality treatments and primary and secondary prevention strategies including lifestyle changes. ${ }^{5}$ 
Management of oral cavity SCC depends on the stage of disease, Stage I and II cancers (T1-T2, N0) are treated with single modality therapy, surgery or radiotherapy (RT) for the primary. Locally advanced cancers (Stage III and IV) are treated with combination of surgery, radiotherapy and chemotherapy for both primary and the neck. ${ }^{6}$ Concurrent chemotherapy with normofractionated RT (2 Gy/day, 5 days/week, for 5-7 weeks) is the most popular approach in current practice. $^{7}$

Complications caused due to treatment of oral cancers are oral mucositis, chemotherapy-induced nausea and vomiting (CINV), nutritional deficiency, fatigue, pain, anxiety and insomnia, gastrointestinal disturbances and radiotherapy related complications like xerostomia, trismus, radiation dermatitis. In oral mucositis to reduce the severity of mucositis and pain various topical preparations like viscous lidocaine, benzocaine, chlorhexidine, and diphenhydramine and topical analgesics used. ${ }^{8}$

Chemotherapy-induced nausea and vomiting (CINV) is the most common side effect which also affects nutritional intake in the patients leading to nutritional deficiencies and fatigue. This can be treated with 5-Hydroxytryptamine 3 (5-HT3) antagonists like dolasetron, granisetron, ondansetron and Neurokinin 1 (NK1) receptor antagonists like fosaprepitant and aprepitant. ${ }^{9}$

Cancer patient are mainly affected by the progressive cachexia, and is one among the major causes where it presents as progressive weight loss, anorexia, and persistent erosion of host body cell mass in response to a malignant growth. ${ }^{10}$ Deficiency of any of the micronutrients needs to be corrected by administering drugs like iron, folic acid and multivitamins. ${ }^{11}$

The pain management has been of critical importance and this has been added as part of routine cancer care by WHO, international and national professional organisations, and governmental agencies. $30-50 \%$ patients with cancer have chronic pain who are undergoing active treatment. ${ }^{12}$ Most of chronic pain constitutes of opioid-based pharmacotherapy and analgesics.

Anxiety is the most common reaction when a person is diagnosed with cancer and a fear arises as it leads to loss of body functions, alterations in appearance, family disruption, death, etc. Anxiety tends to appear or worsen at critical points during the course of the illness (diagnosis, beginning and end of treatment, recurrence, survival and terminal stage). ${ }^{13}$ Sleep disorders are usually associated with the psychological impact on awareness of presence of cancer as well as with the physical illness itself and pain. ${ }^{14}$ Anxiety and sleep disturbances can be controlled by implementing psychotherapy and cognitive behavioural therapy (CBT) with a combination of pharmacological treatment. The pharmacological treatment include alprazolam for anxiety and for sleep disorders - nonbenzodiazepine, benzodiazepine receptor agonists, benzodiazepines, melatonin receptor agonists, antihistamines. $^{15}$

The objective of the study was to find the incidence of chemoradiotherapy related short term adverse effects and its management.

\section{METHODS}

The study was a prospective, observational study and was undertaken for a period of 18 months. The study was conducted in the oncology and ENT wards of Justice K. S. Hegde Charitable Hospital, a tertiary care teaching hospital located in Deralakatte, Mangaluru, India.

The inclusion criteria of our study were patients of either sex and age $>18$ years and newly diagnosed and/or known case of carcinoma which require treatment with chemoradoitherapy for Oral Cancer. Patients with the following conditions were excluded from study - HIV positive patients, other malignancies, pregnant and lactating women.

\section{Collected data}

Oral cancer treatment details, short term effects/ADR (Adverse drug reaction) due to chemoradiotherapy and surgery and data pertaining to the drug therapy (drugs prescribed, fixed dose combination (if any) and usage of generic/ brand name).

\section{Statistical analysis}

Data was tabulated on SPSS (version 16) and analysed as frequency and percentage.

\section{RESULTS}

Our study consisted a total of 79 patients who had oral cancer and were admitted as in-patient in tertiary care teaching hospital. The patients were included in the study based on inclusion and exclusion criteria specified. Total study duration was 18 months.

\section{Oral cancer treatment}

In the observed 79 patients with oral cancer, surgery was done in (44 patients out of 79 patients) and in neo adjuvant chemoradiotherapy group patients were given only chemoradiotherapy (31 patients). Adjuvant chemoradiotherapy group i.e., post-surgery chemoradiotherapy was administered to (45 patients) and radiotherapy was given to most of them (77 patients) (Table 1).

\section{Short term effects/ADR observed in oral cancer treated patients}

The patients who underwent treatment for oral cancer, presented with following side effects. pain (63 patients), 
weight loss (60 patients), reduced appetite (53 patients), fatigue (60 patients), gastritis (53 patients), skin discoloration (40 patients) and anaemia (36 patients). Few of the patients presented with side effects like nausea and vomiting, constipation, insomnia and flap infection (Table 2).

Table 1: Frequency and percentage of treatment given to oral cancer patients.

\begin{tabular}{|lll|}
\hline Treatment & $\begin{array}{l}\text { Frequency } \\
(\mathbf{n = 7 9 )}\end{array}$ & Percentage (\%) \\
\hline Surgery & 44 & $55.7 \%$ \\
\hline Neo Adjuvant CT & 31 & $39.2 \%$ \\
\hline Adjuvant & 45 & $57.7 \%$ \\
\hline Radiotherapy & 77 & $97.5 \%$ \\
\hline
\end{tabular}

Table 2: Frequency of short-term effects/ ADR observed in oral cancer treated patients.

\begin{tabular}{|ll|}
\hline Side effects & Frequency $(\mathbf{n = 7 9})$ \\
\hline Skin discoloration & 40 \\
\hline Weight loss & 60 \\
\hline Reduced appetite & 53 \\
\hline Fatigue & 60 \\
\hline Pain & 63 \\
\hline Gastritis & 53 \\
\hline Anemia & 36 \\
\hline Nausea & 7 \\
\hline Vomiting & 10 \\
\hline Constipation & 16 \\
\hline Insomnia & 8 \\
\hline Flap infection & 2 \\
\hline
\end{tabular}

\section{Usage of generic/ brand name}

A total of 580 drugs were prescribed to the 79 patients, 371 drugs $(64 \%)$ were prescribed under brand name and $212(36 \%)$ by generic name. Patients were given drug prescription ranging from 6 to 15 drugs per patient indicating polypharmacy in high number of patients.

\section{Adjuvant drugs used in oral cancer patients}

A total of 580 drugs prescribed were analysed, out of which drugs used as topical applicant /mouth washes constituted the bulk of the prescriptions (129 prescriptions) followed by drugs used on gastrointestinal system (110 prescriptions), Nutritional supplements (89 prescriptions), NSAIDS/opioids (74 prescriptions), hematinic (73 prescriptions) and drugs acting on respiratory system (50 prescriptions). Other important categories of drugs prescribed included antimicrobials, drugs acting on central nervous system, drugs acting on cardiovascular system and antidiabetic drugs. A minor percentage of drugs belonging to various categories were included thyroxine, dexamethasone, tranexamic acid and potassium chloride which were grouped under miscellaneous category for convenience and they constituted 5 prescriptions (Table 3 ).

Table 3: Frequency of various classes of adjuvant drugs used in oral cancer patients.

\begin{tabular}{|ll|}
\hline Class & Frequency $(\mathbf{n = 5 8 0})$ \\
\hline CVS & 7 \\
\hline Nutritional Supplement & 89 \\
\hline Hematinics & 73 \\
\hline CNS & 8 \\
\hline Antidiabetic & 4 \\
\hline GIT & 110 \\
\hline Respiratory & 50 \\
\hline NSAIDS/Opioids & 74 \\
\hline Antimicrobials & 31 \\
\hline Topical & 129 \\
\hline Miscellaneous & 5 \\
\hline Total & 580.00 \\
\hline
\end{tabular}

\section{DISCUSSION}

There is a high burden of oral cancer in Indian population that accounts for a high prevalence of morbidity and mortality. In this study, adjuvant drugs used to treat short term effects/ ADR's caused due to chemoradiotherapy is being analysed.

It was observed that out of 79 patients with oral cancer, surgery was done for 44 patients. Most of the patient in our study underwent wide local excision of the tumour along with modified radical neck dissection(MRND) to prevent cervical lymph node metastasis and pectoralis major myocutaneous (PMMC) flap reconstruction was done. This is similar to the findings of Jatin P. Shah which showed surgery is the definitive treatment for majority of oral cancers. $^{5}$

Adjuvant chemoradiotherapy accounted upto 57\% and $55 \%$ of patients belong to neo adjuvant chemoradiotherapy group. Alone radiotherapy was upto $97.5 \%$. And according to Renaud Mazeron et al chemotherapy plays an important role in the treatment of locally advanced HNSCC either as concomitant chemoradiotherapy (CT-RT) or as induction chemotherapy. ${ }^{16}$

Most of the patients suffered from side effects caused due to treatment (chemoradiotherapy and surgeries). Most of them had more than 2-3 side effects at the time of treatment and where treated with adjuvant drugs. Major side effects seen were pain 79\%. According to Munro AJ pain accounted for $30 \%$ to $40 \%$ of their main complaints, and is of multifactorial aetiology. ${ }^{17}$ The next common complaint was weight loss $76 \%$, and weight loss after treatment for intraoral malignancy is common and can impair patient recovery and wound healing.

$73 \%$ of the patients complained of oral mucositis, while in A. Rodríguez-Caballero study oral mucositis is the most 
common side effects of radiotherapy and/or chemotherapy. ${ }^{18}$ The next side effect seen more commonly was fatigue $76 \%$ and according to Curt GA et al fatigue prevented them from leading a "normal" life. ${ }^{19}$ Even in our study the patients complained fatigue was affecting their regular daily activities.

Other side effects like anemia $45 \%$ and loss of appetite $38 \%$ are similar to study conducted by Gellrich $\mathrm{N}-\mathrm{C}$, where malnutrition and loss of weight are seen in patients with oral cancer during treatment. Therefore, most of the patients where prescribed multivitamins and other nutritional supplements. ${ }^{20}$ Patients also complained of few gastrointestinal side effects like gastritis, nausea and vomiting, constipation and diarrhea. These findings where consistent to the study done by Thomas Meuser et al where, prophylactic prescription of histamine-2-antagonists, antiemetic's and constipation was started. Even in our study patients where prophylactically started on these medications along with chemoradiotherapy. ${ }^{21}$

Majority of the patients where prescribed topical applicants/ mouth washes (22\% of total no. of adjuvant drugs prescribed) for oral mucositis, infections in oral cavity and pain in mouth. According to study by Elting et al, they observed mucositis during $37 \%$ of chemotherapy cycles. $^{22}$

The nutritional supplements $(15.34 \%)$ was prescribed as the patients had difficulty in opening of mouth, pain while swallowing, pain post-surgery and oral ulcers; they couldn't tolerate spicy, sour and hard foods and eating bland, tasteless food was difficult. All this led to poor nutritional status and therefore most of them where prescribed B protein powder and multivitamins supplements. This was similar in contrast to study by, insufficient calorie intake leading to malnutrition and loss of weight in patients with oral cancer. ${ }^{23-26}$

The NSAIDS/ opioids was prescribed to many patients, who complained of different types of pain (79\%) like tongue pain, mouth pain, pain when swallowing, pain in the palate, burning mouth, gingival pain and pain when chewing. Therefore to relieve pain, systemic drugs $(12.76 \%)$ like tramadol, paracetamol, aspirin and severe pain morphine was prescribed in our study. Along with systemic drugs, local applicants (30\%) like dentogel and smuth ointment which is a local anaesthetic containing lignocaine was used topically as add on. This was similar to findings in study, which revealed most pain in cancer can be controlled by pharmacological treatment with orally administered analgesics, either alone or supplemented with co-analgesic (adjuvant) drugs. ${ }^{26,27}$

Other short term effects caused by chemoradiotherapy and surgery were treated appropriately using drugs. And most of the patients presented with more than one side effect at a given point of time, and treatment of which led to polypharmacy which accounted upto a total of 580 prescriptions of adjuvant drugs.
Our data showed a low percentage of generic drug prescription (36\%) which is a matter of concern. There is a need to promote generic drug prescription in our hospital as the patients are from low socio-economic background and this contributes to lower health care costs and reduce the patients financial burden of treating the illness.

\section{CONCLUSION}

In conclusion, our study has shown that the management of oral cancer in a tertiary care teaching hospital, is in concurrence with the rational utilization of medicines which is based on clinical knowledge, proficiency and the guidelines accessible in the field of oncology practice. Drugs are commonly prescribed in their brand name, instead use of non-proprietary terminology should be encouraged to reduce the financial burden to the patients. It's time to bring about that awareness regarding oral cancer among the population, as it can be diagnosed earlier by self-mouth examination. Early detection has better curing rates and it will also reduce the cost for the treatment.

\section{ACKNOWLEDGEMENTS}

Authors would like to express their gratitude to the department of oncology and department of ENT in Justice K. S. Hegde Charitable Hospital for their co-operation and support throughout the study.

Funding: No funding sources

Conflict of interest: None declared

Ethical approval: The study was approved by the Institutional Ethics Committee

\section{REFERENCES}

1. Chaturvedi AK, Engels EA, Pfeiffer RM, Hernandez BY, Xiao W, Kim E, et al. Human papillomavirus and rising oropharyngeal cancer incidence in the United States. J Clin Oncol Off J Am Soc Clin Oncol. 2011 Nov 10;29(32):4294-301.

2. Scully C, Bagan J. Oral squamous cell carcinoma overview. Oral Oncol. 2009 Apr 1;45(4):301-8.

3. Llewellyn CD, Linklater K, Bell J, Johnson NW, Warnakulasuriya S. An analysis of risk factors for oral cancer in young people: a case-control study. Oral Oncol. 2004 Mar 1;40(3):304-13.

4. Coelho KR. Challenges of the Oral Cancer Burden in India [Internet]. Journal of Cancer Epidemiology. 2012 [cited 2017 Oct 7]. Available at: https://www.hindawi.com/journals/jce/2012/701932/

5. Shah JP, Gil Z. Current concepts in management of oral cancer - Surgery. Oral Oncol. 2009 Apr 1;45(4):394-401.

6. Arya S, Chaukar D, Pai P. Imaging in oral cancers. Indian J Radiol Imaging. 2012;22(3):195-208.

7. Epstein JB, Thariat J, Bensadoun RJ, Barasch A, Murphy BA, Kolnick L, et al. Oral complications of 
cancer and cancer therapy. CA Cancer J Clin. 2012 Nov 1;62(6):400-22.

8. Clinical practice guidelines for the prevention and treatment of cancer therapy-induced oral and gastrointestinal mucositis - Rubenstein; 2004. Cancer - Wiley Online Library [Internet]. [cited 2017 Oct 11]. Available http://onlinelibrary.wiley.com/doi/10.1002/cncr.2016 3/full

9. Musso M, Scalone R, Bonanno V, Crescimanno A, Polizzi V, Porretto F, et al. Palonosetron (Aloxi) and dexamethasone for the prevention of acute and delayed nausea and vomiting in patients receiving multiple-day chemotherapy. Support Care Cancer Off J Multinatl Assoc Support Care Cancer. 2009 Feb;17(2):205-9.

10. Kern KA, Norton JA. Cancer cachexia. JPEN J Parenter Enteral Nutr. 1988 Jun;12(3):286-98.

11. Ames BN. DNA damage from micronutrient deficiencies is likely to be a major cause of cancer. Mutat Res Mol Mech Mutagen. 2001 Apr 18;475(12):7-20.

12. Portenoy RK, Lesage P. Management of cancer pain. The Lancet. 1999 May 15;353(9165):1695-700.

13. Die Trill M. Anxiety and sleep disorders in cancer patients. EJC Suppl. 2013 Sep;11(2):216-24.

14. Ohayon MM, Caulet M, Lemoine P. Comorbidity of mental and insomnia disorders in the general population. Compr Psychiatry. 1998 Aug;39(4):18597.

15. NCCN practice guidelines for the management of psychosocial distress. National Comprehensive Cancer Network. Oncol Williston Park N. 1999 May;13(5A):113-47.

16. Current concepts of management in radiotherapy for head and neck squamous-cell cancer - Oral Oncology [Internet]. [cited 2017 Oct 12]. Available at: http://www.oraloncology.com/article/S13688375(09)00032-3/abstract

17. Bystander effects and their implications for clinical radiotherapy - IOP science [Internet]. [cited 2017 Oct 12]. Available

at: http://iopscience.iop.org/article/10.1088/09524746/29/2A/S09/meta

18. Rodríguez-Caballero A, Torres-Lagares D, RoblesGarcía M, Pachón-Ibáñez J, González-Padilla D, Gutiérrez-Pérez JL. Cancer treatment-induced oral mucositis: a critical review. Int J Oral Maxillofac Surg. 2012 Feb;41(2):225-38.

19. Curt GA, Breitbart W, Cella D, Groopman JE, Horning SJ, Itri LM, et al. Impact of cancer-related fatigue on the lives of patients: new findings from the Fatigue Coalition. The Oncologist. 2000;5(5):353-60.

20. Gellrich NC, Handschel J, Holtmann H, Krüskemper G. Oral cancer malnutrition impacts weight and quality of life. Nutrients. 2015 Mar 27;7(4):2145-60.

21. Symptoms during cancer pain treatment following WHO-guideline: PAIN [Internet]. [cited 2017 Oct 12]. Available at: http://journals.lww.com/pain/Abstract/2001/09000/S ymptoms_during_cancer_pain_treatment_following.7 .aspx

22. Elting LS, Cooksley C, Chambers M, Cantor SB, Manzullo E, Rubenstein EB. The burdens of cancer therapy. Clinical and economic outcomes of chemotherapy-induced mucositis. Cancer. 2003 Oct 1;98(7):1531-9.

23. Stein A, Voigt W, Jordan K. Chemotherapy-induced diarrhea: pathophysiology, frequency and guidelinebased management. Ther Adv Med Oncol. 2010 Jan;2(1):51-63.

24. Jager-Wittenaar H, Dijkstra PU, Vissink A, Langendijk JA, van der Laan BFAM, Pruim J, et al. Changes in nutritional status and dietary intake during and after head and neck cancer treatment. Head Neck. 2011 Jun;33(6):863-70.

25. Guo CB, Ma DQ, Zhang KH. Nutritional status of patients with oral and maxillofacial malignancies. $\mathbf{J}$ Oral Maxillofac Surg Off J Am Assoc Oral Maxillofac Surg. 1994 Jun;52(6):559-64.

26. De Luis DA, Izaola O, Aller R. Nutritional status in head and neck cancer patients. Eur Rev Med Pharmacol Sci. 2007 Aug;11(4):239-43.

27. Symptoms during cancer pain treatment following WHO-guideline: PAIN (Internet). (cited 2017 Oct 12). Available at: http://journals.lww.com/pain/Abstract/2001/09000/S ymptoms_during_cancer_pain_treatment_following.7 .aspx.

Cite this article as: Srinivas M, Volabailu R, Shetty JK, Sharma SN. A study on management of oral cancer in a tertiary care hospital. Int $\mathrm{J}$ Basic Clin Pharmacol 2018;7:278-82. 